\title{
Norwegian Residential Energy Demand: Coordinated use of a System Engineering and a Macroeconomic Model*
}

\author{
TOR ARNT JOHNSEN,$\dagger$ and FRIDTJOF F. UNANDER, $\ddagger$
}

Keywords: Energy, Economy, General equilibrium model, Linear programming model

In Norway, the system engineering model MARKAL and the macroeconomic model MSG-EE are both used in studies of national $\mathrm{CO}_{2}$ controlling strategies. MARKAL is a linear programming model that calculates a composite set of technologies necessary to meet demand and environmental constraints at minimised total energy expenditure. MSG-EE is an applied general equilibrium model including the link between economic activity, energy demand and emissions to air. MSG-EE has a theory consistent description of the link between income, prices and energy demand, but the representation of technological improvements is simple. MARKAL has a sophisticated description of future energy technology options, but includes no feedback to the general economy. A project for studying the potential for a coordinated use of these two models was initiated and funded by the Norwegian Research Council (NFR). This paper gives a brief presentation of the two models. Results from independent model calculations show that MARKAL gives a signficant lower residential energy demand than MSG-EE does. This is explained by major differences in modelling approach. A first attempt of coordinating the residential energy demand in the models is reported. This attempt shows that implementing results from MARKAL in MSG-EE for the residential sector alone gives little impact on the general economy. A further development of an iteration procedure between the models should include all energy using sectors.

\section{Introduction}

Estimating the cost of $\mathrm{CO}_{2}$ emission reductions is a central issue in the greenhouse debate. The cost estimates are closely related to the interaction between economic growth, the level of energy demand and the development of an energy system to supply the demand. Studies of energy/economic consequences of introducing $\mathrm{CO}_{2}$ abatement instruments are often performed by using system engineering models or macroeconomic models. Previous work by e.g. Manne and Wene (1992) indicates that the two modelling philosophies may give different effects on future energy demand. System engineering models with detailed descriptions of future technology options, but with no feedback to the general economy and ignoring non-technical market factors, tend to show a higher potential for energy savings at less costs than macroeconomic models do. On the other hand macroeconomic models tend to ignore saturation effects and often have a simple specification of the energy using capital stock and technological progress.

In Norway, the system engineering model MARKAL and the macroeconomic

\footnotetext{
Received 8 June 1994.

*An early version of this paper was in the Proceedings of the 16th Annual Conference of the International Association for Energy Economics, 27-29 July 1993, Bali, Indonesia, REDECON, Jakarta 12910 Indonesia.

†Statistics Norway, P. O. Box 8131, Dep. N-0033, Oslo, Norway.

$\ddagger$ Institutt for energiteknikk, P. O. Box 40, N-2007 Kjeller, Norway.
} 


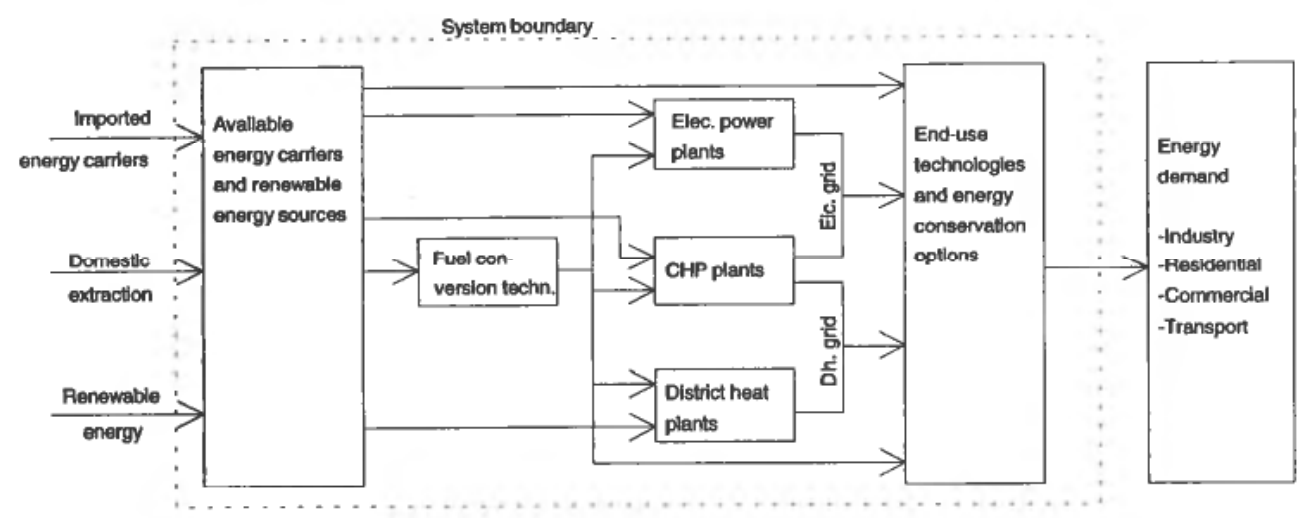

Figure 1. Structure of the MARKAL model.

model MSG-EE are both used in studies of national $\mathrm{CO}_{2}$ controlling strategies. In this paper we discuss the potential for coordinating these two models. The first experiments from informal linkage of MARKAL with other models were by Hoffmann and Jorgenson (1977). A formal linkage of MARKAL with a macroeconomic growth model is reported in Manne and Wene op. cit.

In section 2 and 3 of this paper we describe the main features of MARKAL and MSG-EE, respectively, with a special focus on the residential sector. Section 4 presents the results from separate use of the models, while a first attempt on coordinating the models is reported in section 5. Section 6 concludes this study.

\section{The MARKAL Model}

MARKAL (MARKet ALlocation), Fishbone et al. (1983) is a software package designed to represent national, regional or local energy systems. The first versions of MARKAL were developed in the late 70's under the IEA-project ETSAP (Energy Technology System Analysis Programme). The model has been continuously improved, and in 1989 a PC-version of MARKAL was available.

An illustration of the structure in the MARKAL model is given in Figure 1. The energy system is described through a set of available and prospective technologies for extracting, converting and using energy. Technologies for energy conservation are also included, and compete with supply options. The model chooses among the technologies to identify the optimal energy system that satisfies different technical, economic, and environmental constraints over a time horizon, usually of $40-50$ years. MARKAL is demand driven, i.e. the model has to satisfy projected demand for energy services, measured as useful energy, in each sector.

MARKAL identifies the optimal energy system by solving it as a linear program. An objective function, the total discounted cost, is minimised given a set of constraints that secures that demand, emission limits, capacity requirements, etc. are satisfied. The optimization is done simultaneously for the whole time period analyzed, with a "perfect foresight" that reflects the activities of policy-makers as they are assumed to "know the future". Environmental requirements can be specified by direct restrictions, for example maximum allowable annual emissions of $\mathrm{CO}_{2}$, or by penalizing the emissions (e.g. by a "carbon-tax").

Each technology in the model is characterized through its technical, economic, and 
environmental properties. Institutional and market barriers are assumed to reflect the maximum potential for some technologies. There are also restrictions on the speed of market penetration for new technologies, as well as lower limits on the depreciation of existing technologies in order to avoid unrealistic solutions.

The main demand sectors, industry, residential, services and transport are further divided into several sub-sectors, each with a number of alternative end-use technologies for conversion of final energy to useful energy. For every sub-sector a projection for useful energy demand has to be established outside the MARKAL-model. These projections are calculated as a function of two parameters:

- The activity level of the sub-sector (e.g. production value, heated area, transport $\mathrm{km})$.

- The energy intensity of the demand (useful energy per activity unit).

The latter ones are estimated from historical data and assumptions about autonomous energy efficiency improvements (improvements that are not modelled explicitly through technology descriptions in the model), future insulation standards, etc. The activity levels are based upon macroeconomic calculations that are consistent with the key assumptions in the MARKAL-analysis.

In the calculation of the demand projections in the residential sector, the sector is split into four sub-sectors:

- New single-family houses (S)

- New multi-family houses (T)

- Old single-family houses (U)

- Old multi-family houses (V)

The new single-family and multi-family houses group consist of houses built after 1985 , and thus all future buildings are accumulated in these two groups. The number of buildings in the two groups of old houses is at its maximum in the base year and is thereafter gradually reduced through depreciation of the buildings in this category. The net total growth in the number of buildings is based upon population projections and assumptions of the development in the number of individuals per unit in each building group.

The heated area per building for new buildings is based upon assumptions of future building size, and for old buildings on statistics on historical building size and expected depreciation rate of buildings from different time periods. Multiplying the heated area for each group $\left(\mathrm{y}_{\mathrm{i}}\right)$, and the number of units in each group $\left(\mathrm{n}_{\mathrm{i}}\right)$ gives the activity level, heated area per group

$$
\mathrm{m}_{\mathrm{i}}=\mathrm{n}_{\mathrm{i}} \mathrm{y}_{\mathrm{i}},
$$

where $\mathrm{m}_{\mathrm{i}}$ is heated area measured in millions square meters. For each of the building groups it is assumed a time varying energy intensity $\left(\alpha_{i j}\right)$ for appliances $(j=A)$, heating $(j=H)$ and water heating $(j=W)$. For old buildings the intensities for heating are based on historical data on insulation standards and energy consumption. For the new buildings the intensities are based upon assumptions of future insulation standards. The intensities for water heating are assumed to depend on the number of occupants, and on the building size. The energy intensities for appliances are estimated from an assumed increase in the use of the equipment and from a development of the energy efficiency. Total useful energy demand in the residential sector $\left(\mathrm{X}^{\mathrm{U}}\right)$ is defined as the 
activity levels times the useful energy intensity $(\mathrm{j}=\mathrm{A}, \mathrm{H}, \mathrm{W})$ in the four building groups $(\mathrm{i}=\mathrm{S}, \mathrm{T}, \mathrm{U}, \mathrm{V})$

$$
\mathrm{X}^{\mathrm{U}}=\sum_{\mathrm{i}} \sum_{\mathrm{j}} \alpha_{\mathrm{ij}} \mathrm{m}_{\mathrm{i}}
$$

MARKAL chooses among end-use technologies in order to satisfy these projections of useful energy demand to a minimum cost given certain constraints. Depending on the utilization of conservation options and the efficiencies of the technologies chosen in the solution, MARKAL calculates the resulting final energy demand $\left(\mathrm{X}^{\mathrm{F}}\right)$,

$$
X^{F}=\sum_{i} \sum_{j} \frac{\alpha_{i j}}{\mu_{i j}} m_{i},
$$

where $\mu_{\mathrm{ij}}$ is the efficiency for each type of end use, $\mathrm{j} . \mu_{\mathrm{ij}}$ represents the conversion efficiency of the technologies and contribution from saving options like heat pumps, solar heat and conservation options.

\section{The MSG-EE model}

MSG (Multi Sectoral Growth) is an applied general equilibrium macroeconomic model of the Norwegian economy originally developed by Professor Leif Johansen, Johansen (1960). MSG-EE (EE for energy and environment) is a version of the MSG-model with a disaggregated modelling of features of special importance for the energy market and the environment. Figure 2 describes the structure of the model. Price and quantity input-output structures form the core of the model. The price submodel determines domestic prices of 40 different goods,

$$
\sum_{h=1, \ldots, 30} \gamma_{h j} B_{h}=\sum_{i=K, L, U, M, T} z_{i j} p_{i j}
$$

where the left hand side is a weighted sum of the prices $\left(B_{h}\right)$ of goods produced in the sector $\mathrm{j}$. The weights $\left(\gamma_{\mathrm{hj}}\right)$ are constant and equals the base year production of commodity $\mathbf{h}$ in sector $\mathbf{j}$ as share of the total production of sector $\mathbf{j}$. The unit cost in production sector $\mathrm{j}$ is the right hand side of equation 3 . The unit cost in sector $\mathrm{j}$ is a weighted sum of input prices $\left(\mathrm{p}_{\mathrm{ij}}\right)$, where the weights $\left(\mathrm{z}_{\mathrm{ij}}\right)$ are estimated input coefficient functions ${ }^{1}$

$$
\mathrm{z}_{\mathrm{ij}}=\mathrm{z}_{\mathrm{ij}}\left(\mathrm{p}_{\mathrm{Kj}}, \mathrm{p}_{\mathrm{Lj}}, \mathrm{p}_{\mathrm{Uj}}, \mathrm{p}_{\mathrm{Mj}}, \mathrm{p}_{\mathrm{Tj}}\right)
$$

The input coefficients depend on sector specific input prices $\left(\mathrm{p}_{\mathrm{ij}}\right)$ of the input factors capital (K), labour (L), energy (U), materials (M) and transport (T). These factor prices are aggregates of the prices of different goods and exogenous prices (rate of return to capital, wages, crude oil price, import prices and tax rates).

The interest rate is exogenous and the capital formation is endogenous. Technical progress in the production sectors is exogenous, but can be factor specific. The assumptions concerning the labour supply, technical progress and the trade balance limit the gross production in the economy. Export demand is modelled by Armington functions, that is, export depends on the domestic prices relative to the world market prices and on international market indicators for the commodities. The import share for a commodity depends on price of import and the domestic price. The trade balance is exogenously given and the total value of net export is set exogenous to control net

\footnotetext{
${ }^{1}$ Gencralized Leontief functions (GL).
} 


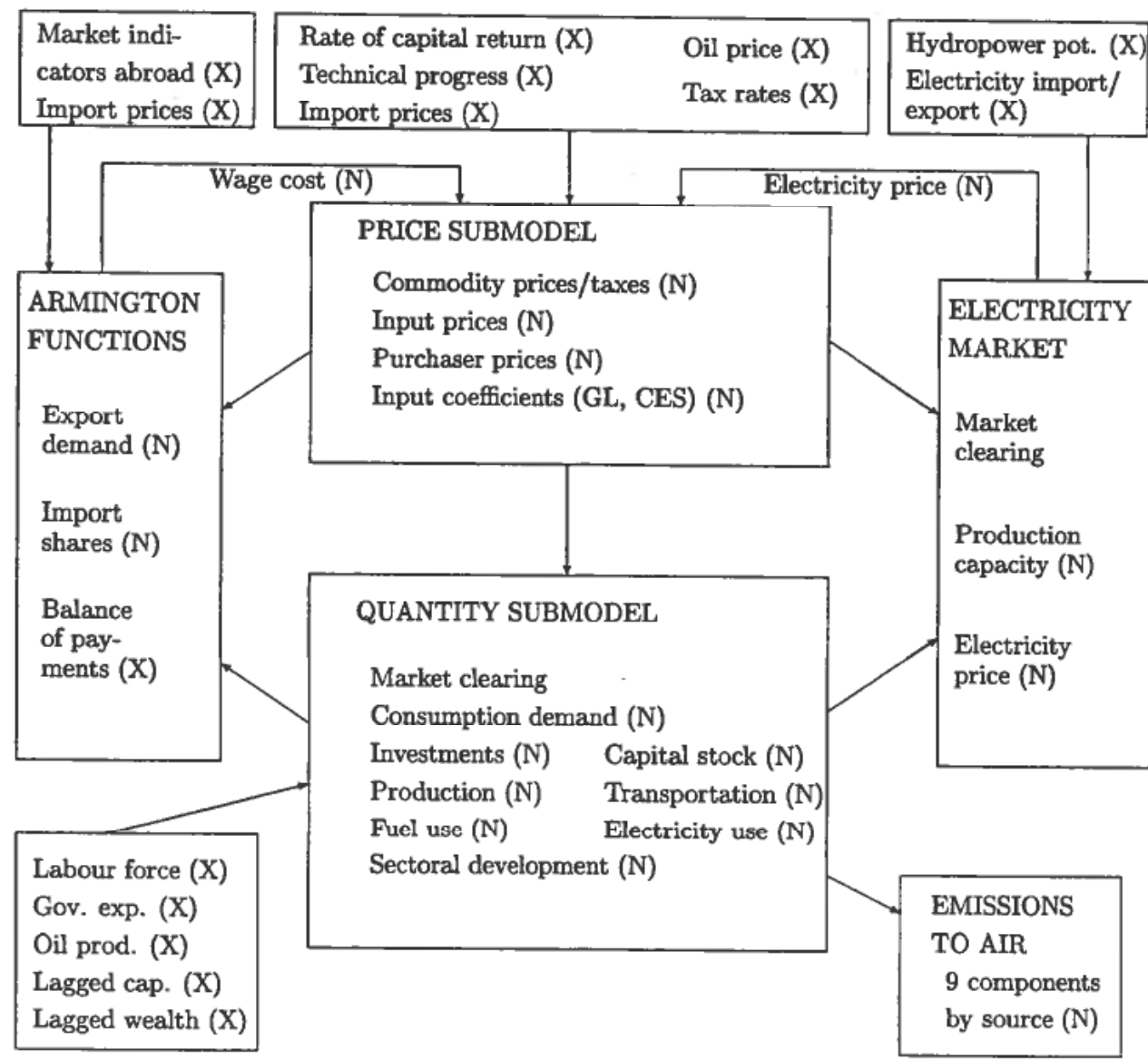

Figure 2. Structure of the MSG-EE model. Some exogenous (X) and endogenous (N) variables.

foreign wealth. The supply of labour is exogenous. To clear labour market the wage rate then has to be endogenous.

The sectoral prices of electricity are endogenous in the model. The demand and supply of electricity determine an equilibrium electricity price. The supply curve is given by potential hydro power projects and by the cost of gas-fired thermal power. Exports and imports of electricity can be specified exogenously. The quantity input-output block ensures that supply equals demand for each of the commodities in the model,

$$
\mathbf{I}_{\mathrm{h}}+\sum_{\mathrm{j}} \gamma_{\mathrm{hj}} \mathbf{X}_{\mathrm{j}}=\mathbf{C}_{\mathrm{h}}+\mathbf{J}_{\mathbf{h}}+\mathrm{G}_{\mathrm{h}}+\mathbf{A}_{\mathrm{h}},
$$

where the left hand side is the supply of commodity $\mathrm{h}$ which equals the sum of imports $\left(\mathrm{I}_{\mathrm{h}}\right)$ and domestic production $\left(\Sigma_{\mathrm{j}} \gamma_{\mathrm{hj}} \mathrm{X}_{\mathrm{j}}\right)$. The demand for commodity h equals the sum of consumption $\left(C_{h}\right)$, gross investment $\left(J_{h}\right)$, government demand $\left(G_{h}\right)$ and export $\left(A_{h}\right)$.

A submodel calculates emissions to air of 9 different emission components by source. This submodel is of special importance when focusing on emission analyses. 
An estimated linear expenditure system (LES) determines the household sector demand for 16 different goods, see Aasness and Holtsmark (1993). The utility function is

$$
\mathbf{U}=\sum_{\mathbf{j}} \beta_{\mathrm{j}} \log \left(\mathbf{c}_{\mathbf{j}}-\gamma_{\mathrm{j}}\right),
$$

where $\beta$ is the marginal budget share for good $\mathbf{j}, \mathbf{c}_{\mathbf{j}}$ is consumption of good $\mathbf{j}$, and $\gamma_{\mathbf{j}}$ may be interpreted as a minimum consumption of good $\mathrm{j}$. Maximization of the utility given the budget constraint

$$
\sum_{j} p_{j} c_{j}=y,
$$

where $\mathrm{p}_{\mathrm{j}}$ is the price of good $\mathrm{j}$, and $\mathrm{y}$ is the total household expenditure, gives the demand function

$$
c_{\mathrm{j}}=\gamma_{\mathrm{j}}+\beta_{\mathrm{j}}\left(\frac{\mathrm{y}-\mathrm{m}}{\mathrm{p}_{\mathrm{j}}}\right)
$$

where $\mathrm{m}=\Sigma_{\mathrm{j}} \mathrm{P}_{\mathrm{j}} \gamma_{\mathrm{j}}$. In the model, the parameter $\gamma_{\mathrm{j}}$ depends on the number of households $(\mathrm{NH})$, children $\left(\mathrm{z}_{1}\right)$ and adults $\left(\mathrm{z}_{2}\right)$ in the economy through estimated relations of the form

$$
\gamma_{\mathrm{j}}=\gamma_{\mathrm{j} 0} \mathrm{NH}+\gamma_{\mathrm{j} 1} \mathrm{z}_{1}+\gamma_{\mathrm{j} 2} \mathrm{z}_{2}
$$

Energy for stationary use and private and public transportation are separate in the LES expenditure system. The households stationary energy demand $\left(c_{U}\right)$ is a CES ${ }^{2}$ aggregate of electricity $\left(c_{E}\right)$ and heating fuels $\left(c_{F}\right)$ (both solid and liquid fuels),

$$
\mathrm{c}_{\mathrm{U}}=\mathrm{CES}(\mathrm{E}, \mathrm{F})=\left[\delta \mathrm{c}_{\mathrm{E}}^{-\rho}+(1-\delta) \mathrm{c}_{\mathrm{F}}^{-\rho}\right]^{\frac{-1}{\rho}}
$$

In MSG-EE, $c_{E}$ and $c_{F}$ are in terms of final energy.

Applying Shephard's lemma we find the demand for electricity and fuels respectively as

$$
\mathrm{c}_{\mathrm{E}}=\left(\delta \frac{\mathrm{p}_{\mathrm{u}}}{\mathrm{p}_{\mathrm{E}}}\right)^{\sigma} \mathrm{c}_{\mathrm{U}}
$$

and

$$
\mathrm{c}_{\mathrm{F}}=\left((1-\delta) \frac{\mathrm{p}_{\mathrm{u}}}{\mathrm{p}_{\mathrm{F}}}\right)^{\sigma} \mathrm{c}_{\mathrm{U}}
$$

where $p_{u}$ is the endogenous price of energy

$$
\mathrm{p}_{\mathrm{u}}=\left[\delta^{\sigma} \mathrm{p}_{\mathrm{E}}^{\frac{1}{-\sigma}+}+(1-\delta)^{\sigma} \mathrm{p}_{\mathrm{F}}^{\frac{1}{-\sigma}}\right]^{\frac{1}{1-\sigma}}
$$

In the present version of the model the estimated elasticity of substitution

$$
\left(\sigma=\frac{1}{1+\rho}\right)
$$

between electricity and fuels is equal to 0.5 . In our LES-system the marginal consumption propensity for energy is estimated to 0.017. In 1988 the budget share of energy was 0.063 . The income elasticity for given demographic condition is then approximately $0 \cdot 3$.

The parameters determining energy demand in MSG-EE are estimated using empirical data. In the consumer model, housing expenditures can substitute energy.

\footnotetext{
${ }^{2}$ Constant Elasticity of Substitution.
} 
Included in housing expenditures are insulation outlays, investments in heating equipment and energy using durables.

\section{Results from single model use}

Table 1 reports the residential energy demand computed in two studies with the MARKAL and MSG-EE model, respectively. The exogenous input in both studies is based on Moum (1992).

Table 1. Development of energy demand in the residential sector [TWh]

\begin{tabular}{lrcc}
\hline & 1990 & \multicolumn{2}{c}{2020} \\
\cline { 3 - 4 } & & MARKAL & MSG-EE \\
\hline Electricity & $30 \cdot 7$ & $32 \cdot 0$ & $37 \cdot 1$ \\
Oil & $5 \cdot 3$ & $0 \cdot 5$ & $6 \cdot 4$ \\
Wood & $5 \cdot 7$ & $7 \cdot 0$ & 6.7 \\
District heat & $0 \cdot 3$ & 1.6 & $* *$ \\
\hline = Final energy demand & $42 \cdot 0$ & $41 \cdot 1$ & $50 \cdot 2$ \\
\hline + Saving options & - & $2 \cdot 5^{*}$ & \\
\hline - Consumer conversion losses & $4 \cdot 7$ & 4.5 & \\
\hline = Useful energy demand & $37 \cdot 3$ & 39.1 & \\
\hline
\end{tabular}

*Contributions from heat pumps, solar heat, and conservation options, not considered as final energy.

**District heat is included in electricity in MSG-EE.

The residential energy demand was about 42 TWh in the base year (1990). According to MARKAL final energy demand decrease with 0.9 TWh from 1990 to 2020 . The MSG-EE study predict a 20 percent or 8.2 TWh growth in residential energy demand through the same period ( $0.6 \% / y e a r)$. In the same period, total household expenditure increases with $2 \cdot 2 \%$ year.

The useful energy demand in 2020 in the MARKAL-study is calculated in equation 2 . The growth in useful energy demand in the MARKAL study is very low, only $1 \cdot 8 \mathrm{TWh}$ through the 30 year period from 1990 to 2020 (0.16\%/year).

The low growth rate of useful energy demand in MARKAL is to a large extent explained by the exogenously assumed improvements of the energy intensities, and by the assumption that income growth is not leading to increased heated area per house. The development of the intensities and the heated area for the different building categories are based upon figures from NBI. ${ }^{3}$ (For a presentation of the figures, see Unander (1993)).

The heated area per building is assumed constant throughout the calculation period. The energy intensity for heating is assumed to steadily decrease due to improvement of the insulation standard of the dwelling stock. The income growth is assumed to result in replacement of old buildings with low insulation standard with new dwellings with better insulation. The energy intensities for appliances are assumed to be constant. More energy efficient equipment is assumed to balance out the increased use of appliances motivated by higher income. The energy intensity for water heating is assumed to rise slightly reflecting effects of higher income.

\footnotetext{
${ }^{3}$ The Norwegian building research institute.
} 
MSG-EE determines the residential energy demand endogenously through income and price effects and the number of households. An increase in income and in the number of households results in increased energy demand. Increasing energy prices relative to the prices of other consumption goods reduce the energy demand. The MSG-EE results imply that the positive effects on energy demand from demographic changes and increase in income are stronger than the negative effects of increased energy prices. Although the MSG-EE model predicts higher residential energy demand than MARKAL, the predicted growth in MSG-EE is historically low. In the period $1950-90$ residential energy use increased by 2.5 percent per year.

Table 1 also presents the contribution of different energy carriers in satisfying the energy demand. The energy savings by utilisation of solar heat, heat pumps and conservation options are also shown. The results of the calculations in MARKAL gives a detailed picture of the structure of the residential energy demand. The distribution of energy demand on different energy carries and technologies is determined by minimising the energy costs. The calculations show that saving options account for 2.5 TWh in 2020.

The energy use computed in MSG-EE is concentrated on electricity and fossil fuels, the two energy carries in the CES energy-aggregate. The distribution between wood and oil within the fossil fuel aggregate is fixed and equal to the base year composition. In contrast to MARKAL MSG-EE have no explicit costs for the different heating systems modelled. The table shows that MSG-EE does not predict any strong substitution between fossil fuels and electricity because the electricity and fossil fuel prices in the model are growing at nearly the same rate. It is only changes in the relative price of fossil fuel to electricity that will affect substitution.

\section{Coordinate use of the models}

In order to make a first attempt to coordinate the two models the following strategy was chosen:

1. Adjust the exogenous input assumptions in MARKAL so that they include income effects on the residential energy demand more coherently with the way it is modelled in MSG-EE.

2. Run MARKAL with the adjusted usefil energy demand to calculate the composition of the energy system that minimises the energy expenditure.

3. Adjust the distribution of energy use on different energy carriers in MSG-EE according to the results from the MARKAL calculations.

To include income effects on the residential energy demand in MARKAL that are in accordance with MSG-EE, the activity level, heated area, was adjusted to reflect the income elasticity in MSG-EE (0.3). Using this and an income growth of $2.2 \%$ growth per year yield a $22 \%$ increase in the heated area from 1990 to 2020 . This growth rate was implemented for all building categories.

The intensities for heating were not changed assuming the same development of insulation standards as before. The intensities for appliances are assumed to improve by $0.5 \%$ year, yielding a net growth in the electricity demand for appliances of $0.16 \% / y e a r$. The total effect of demographic changes and technical factors as more efficient shower heads is included in an assumed $0.4 \%$ yearly reduction of the intensity for water heating.

Table 2 shows the results from the calculations with MARKAL when the above 
modifications are included. The growth in heated area increases the residential oil and electricity use by $2.7 \mathrm{TWh}$ and $3.8 \mathrm{TWh}$, respectively. The final energy demand in MARKAL is now 2.3 TWh less than in the MSG-EE scenario reported in Table 1 . Future saving options as heat pumps and solar heat are not represented in MSG-EE. Conservation options are in MARKAL modelled explicitly, while in MSG-EE conservation is only implicitly taken into account through historically estimated capital-energy substitution. Without the contribution from the saving options in MARKAL, the resulting final energy demand would have been $0.7 \mathrm{TWh}$ higher than in MSG-EE.

Table 2. Energy demand in the residential sector when the two models are coordinated [TWh]

\begin{tabular}{|c|c|c|c|}
\hline & \multirow[t]{2}{*}{1990} & \multicolumn{2}{|c|}{2020} \\
\hline & & MARKAL & MSG-EE \\
\hline Electricity & $30 \cdot 7$ & $35 \cdot 8$ & 37.2 \\
\hline Oil & $5 \cdot 3$ & $3 \cdot 2$ & 4.7 \\
\hline Wood & 5.7 & $7 \cdot 3$ & $5 \cdot 0$ \\
\hline District heat & $0 \cdot 3$ & 1.6 & $* *$ \\
\hline$=$ Final energy demand & $42 \cdot 0$ & 47.9 & $46 \cdot 9$ \\
\hline + Saving options & - & $3 \cdot 0^{*}$ & \\
\hline - Consumer conversion losses & $4 \cdot 7$ & $5 \cdot 4$ & \\
\hline$=$ Useful energy demand & $37 \cdot 3$ & $45 \cdot 5$ & \\
\hline
\end{tabular}

*Contributions from heat pumps, solar heat, and conservation options, not considered as final energy.

**District heat is included in electricity in MSG-EE.

The results from the MARKAL calculations were used to correct exogenously the residential energy demand in MSG-EE. This was done by adjusting the energy aggregate to reduce the oil/wood use, and by increasing the household's expenditure on housing to reflect the implementation of conservation options. The resulting energy demand is shown in the right hand part of Table 2. Final energy demand in MSG-EE is reduced by $3.3 \mathrm{TWh}$, close to the contribution from saving options in MARKAL.

Investigating the results from MSG-EE show that the corrections made to the residential sector gave no significant impact on the activity levels in the economy. The consequences of changes in the energy system as identified by MARKAL are likely to be higher in sectors where the activity level is more sensitive to costs. This could lead to structural changes, reallocation of capital and labour, and thereby have impact on economic growth. This could in turn change the energy demand. An argument for including all energy using sectors in an iterative model use is that the energy prices are dependent on the activity level in all sectors. In our analysis the electricity price came out higher in the MSG-EE simulations than in MARKAL, due to different electricity demand in other sectors. By adjusting the activity levels in MARKAL, and by adjusting the CES aggregates, and the total energy demand in MSG-EE for all sectors the price of electricity should be more similar in the two models.

Environmental constraints as a carbon tax would lead to increased energy prices, and to changes in relative prices between energy carriers. MARKAL would respond to this by fuel shifts and by utilisation of more efficient technologies including new saving options. In MSG-EE the response to rising prices is slower than in MARKAL. 
One explanation for this is that the price responses in MSG-EE are modelled using historical estimated data. This approach includes impacts of non-technical market barriers, but give low substitution possibilities through technological progress.

\section{Conclusions and further work}

In this paper we have highlighted some of the most important features of the models MARKAL and MSG-EE. Results from separate use of the models illustrate the differences in modelling approaches. An attempt of coordinating the residential sectors in the models showed that including income effects in MARKAL, coherent with the way it is modelled in MSG-EE, increased the residential energy demand in MARKAL to a level close to the results from MSG-EE, when the contribution from future saving options in MARKAL are excluded. These options reduce the energy demand by 6 percent in year 2020. The results of adjusting energy use in MSG-EE to reflect saving options and fuel switch in MARKAL, for the residential sector alone showed that this had little impact on the general economy.

By including all energy using sectors in an iterative linkage between the models a more complete representation of the interaction between technological changes, energy prices, structural effects and economic growth can be achieved.

A strategy for this iterative link can be summarised:

1. Use MSG-EE to calculate the activity levels in each sector. Adjust the useful energy demands in MARKAL to include this development of activity levels.

2. Use MARKAL to minimise the costs of supplying the energy demand. Based upon the MARKAL solution modify the CES energy aggregates and the substitution between energy and capital in MSG-EE to reflect fuels shifts and investments in new technologies.

3. Calculate new activity levels in MSG-EE with these modifications.

4. Repeat the iteration until convergence is reached.

REFERENCES

AASNESS, J., and HolTSMARK, B. (1993). Consumer demand in a general Equilibrium Model for Environmental Analysis. Discussion Papers 105, Statistics Norway. Oslo, Norway.

FISHBONE, L. G. et al. (1983). User's Guide for MARKAL (BNL/KFA Version 2.0), BNL 51701. Brookhaven National Laboratory, Upton, N.Y. 11973.

HoffmANn, K. C., and JoRGENSON, D. W. (1977). Economic and Technological Models for the Evaluation of Energy Policies. The Bell Journal of Economics, vol. 8, no. 12.

JOHANSEN, L. (1960). A Multi-Sectoral Study of Economic Growth, North Holland Publishing Company, Amsterdam, Netherlands.

MANNE, A. S., and WENE, C.-O. (1992). MARKAL-MACRO: A Linked Model for EnergyEconomy Analysis, BNL-47161. Brookhaven National Laboratory, Upton, N.Y. 11973.

Moum, K. (1992). Klima, økonomi og tiltak (KLØKT). Report 92/3, Statistics Norway, Oslo, Norway. (In Norwegian).

UnANDER, F. (1993). $\mathrm{CO}_{2}$ Emission Control in Norway. Results from IEA-ETSAP Annex IV, IFE/KR/E-92/008. Institutt for energiteknikk, Kjeller, Norway. 